\title{
The Analysis of New Generation Mobile Device Dependencies of Students in Faculty of Education
}

\author{
Agah Tuğrul KORUCU* \\ Ahmet Kelesoglu Faculty of Education, Department of Computer Education and Instructional \\ Technology, Necmettin Erbakan University, Konya, Turkey
}

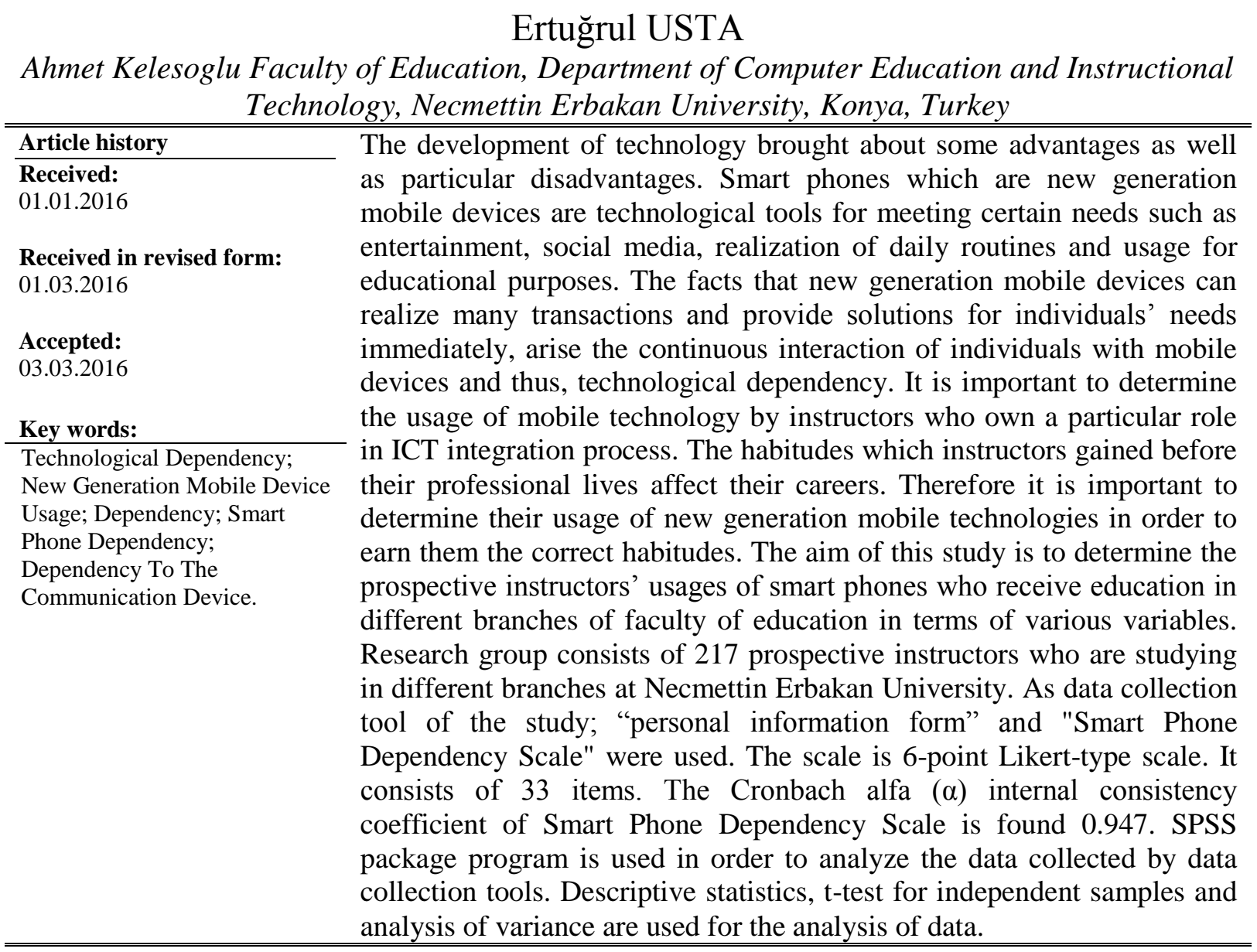

\section{Introduction}

In line with technological developments, the concept of mobile learning is being more and more mentioned and studies regarding the usages of these devices in educational process have become widespread and as a result of this, the concept of m-education occurred. Mobile devices which are among the newest technologies in today's world, are very advantageous in terms of their provision of more time and place to users and being cheaper when compared to 
desktop computers (Oran and Karadeniz, 2007). Studies recently conducted in literature demonstrate that most students now possess smart phones available for operating mobile applications. The causes of smart phone usage by individuals are social needs, effect of environment, dependency, simplification of life etc. (Park and Chen, 2007; Wilson and McCarthy, 2010; Campbell, 2007; Hjorthol, 2008; Kim, 2008; Taner, 2013).

Studies conducted regarding mobile learning in our country are mostly descriptive; experimental studies do not exist at all. However it is possible to run across experimental studies in the literature. Within these studies the following issues are handled; the effects of mobile learning to academic success, attitudes and perceptions of students in various areas, attitudes and perceptions of instructors, applicable mobile environments, collaborative mobile environments, self-regulatory learning in mobile environments, the effects of different provisions of information in mobile environments, game-based mobile learning, note-taking using mobile tools, mobile applications in informal education and increased reality in mobile environments (Korkmaz, 2015).

Sharples and friends (2005) and Cochrane (2010) state that the most important difference of mobile learning among other learning types is the ability of continuous movement of learners. Quinn (2000) defines mobile learning as using hand devices for learning. This first description of Quinn (2000) is being debated and has changed a bit, however it is adopted essentially. According to Çakır (2011), a mobile learning shall include situations in which the particular part of learning is realized outside of schools by which people structure their activities making educational processes and results possible. Owing to the easy accessibility and portability of mobile technologies, learning activities such as exercising and application can be moved out of the classrooms (Saran, Seferoğlu and Çağıltay, 2009).

It can be stated that a lot of issues exist to be discussed based upon the subjects to be considered in the design of these environments regarding mobile learning. One of these discussion-worth issues is dependency which is perceived as an important illness and problem in our world. New mobile technologies began to affect the daily lives of individuals deeply and provided the connection of people to virtual networks continuously and from everywhere. When considered that mobile phones are an important part of daily lives of individuals, the following questions come up; is the mobile phone usage a dependency? Is it a stimulation disorder? Or is it a dependency? According to DSM-IV-TR (2005), stimulation control disorder is defined as a repetitive and irresistible behavior and the difficulty of resisting the realization of a behavior harmful to self or another. The determination of dependency situations of individuals on these devices and environments which these devices provide will be the first stage in overcoming prospective possible problems. Within this scope, the aim of this study is the determination of smart phone usages of prospective students in different branches of faculty of education in terms of various variables. The answers are sought for the following questions within this general goal:

(1) Do smart phone dependencies of students in faculty of education differ in terms of their genders?

(2) Do smart phone dependencies of students in faculty of education differ in terms of their departments?

(3) Do smart phone dependencies of students in faculty of education differ in terms of their classes?

(4) Do smart phone dependencies of students in faculty of education differ in terms of their socio-economic levels? 
(5) Do smart phone dependencies of students in faculty of education differ in terms of their situations of owning their own internet?

(6) Do smart phone dependencies of students in faculty of education differ in terms of their weekly internet usage durations?

\section{Method}

\section{The Model of the Study and the Workgroup}

Conducted according to the screening model, this study comprises of 217 students from the Department of Computer and Instructional Technologies, the Department of Art Teaching, and the Department of Pre-school Teaching within the body of Ahmet Keleşoğlu Faculty of Education, University of Necmettin Erbakan in the academic year 2014-2015 Spring.

\section{Data Collection Tools}

As data collection tool of the study; "personal information form" and "Smart Phone Dependency Scale" developed by Demirci and friends (2014) are used. The scale is 6-point Likert-type scale. It consists of 33 items and 7 dimensions. The Cronbach alfa $(\alpha)$ internal consistency coefficient of Smart Phone Dependency Scale is found 0.947.

\section{Data Analysis}

SPSS (The Statistical Package for The Social Sciences) package program is used in order to analyze the data obtained in scope of the study and all hypotheses are tested in 0.95 reliability level $(\mathrm{p}=0.05)$. Descriptive statistics, $\mathrm{t}$-test for independent samples and analysis of variance are used for the analysis of data. Parametric tests are used during the data analysis because the data correspond to parametric test assumptions. Within this concept, tests used for each sub-goal are explained below.

Demographical data collected from the participants are clarified with descriptive statistical methods. T-test for unrelated samples is used in order to test whether the competence level differs reasonably according to the genders and internet possession situations of the participants. Moreover, single factoral analysis of variance (Anova) for unrelated samples is used in order to test whether the grades obtained by the participants from the scale differs reasonably in terms of weekly internet usage durations, socio-economic levels, class levels and departments of the participants.

\section{Findings and Interpretations}

Table 1 demonstrates the descriptive results regarding the genders of students in the workgroup.

Table 1. Genders of the workgroup

\begin{tabular}{ccc}
\hline Genders & $\mathrm{N}$ & $\%$ \\
\hline Male & 64 & 29,5 \\
Female & 153 & 70,5 \\
\hline Total & 217 & 100,0 \\
\hline
\end{tabular}

As it is clear in Table 1, among the students who participated in the study, 64 are male 
$(29,5 \%)$ and 153 are female $(70,5 \%)$. Table 2 demonstrates the descriptive results regarding the internet possession situations of students in the workgroup.

Table 2. Internet possession situations of the workgroup

\begin{tabular}{ccc}
\hline Possession of Internet & $\mathrm{N}$ & $\%$ \\
\hline Yes & 199 & 91,7 \\
No & 18 & 8,3 \\
\hline Total & 217 & 100,0 \\
\hline
\end{tabular}

As it is clear in Table 2, among 217 students who participated in the study, 199 have access to internet $(91,7 \%)$ while 18 don't have $(8,3 \%)$. Table 3 demonstrates the descriptive results regarding the weekly internet usage durations of the workgroup.

Table 3. Weekly internet usage durations of the workgroup

\begin{tabular}{ccc}
\hline Weekly Internet Usage & $\mathrm{N}$ & $\%$ \\
Durations & & \\
\hline 0-3 hours & 23 & 10,6 \\
3-6 hours & 50 & 23,0 \\
6-9 hours & 45 & 20,7 \\
9 hours and over & 99 & 45,6 \\
\hline Total & 217 & 100,0 \\
\hline
\end{tabular}

As it is clear in Table 3, among 217 students who participated in the study, 23 use 0-3 hours of internet weekly, 50 use 3-6 hours, 45 use 6-9 hours and 99 use 9 hours and over. Table 4 demonstrates the descriptive results regarding the distribution of students in the workgroup in terms of their educational departments.

Table 4. Distribution of students in terms of their educational departments

\begin{tabular}{ccc}
\hline Departments & $\mathrm{N}$ & $\%$ \\
\hline Pre-school & 36 & 16,6 \\
CIT & 141 & 65,0 \\
Art & 40 & 18,4 \\
\hline Total & 217 & 100,0
\end{tabular}

As it is clear in Table 4, among 217 students who participated in the study, 36 receive education in the Pre-school Teaching Department, 141 in CIT Teaching Department, 40 in Art Teaching Department. Table 5 includes the findings concerning whether the grades which participants obtained from the smart phone dependency scale reasonably differ or not in terms of the departments of students.

Table 5. Results of grades according to departments

\begin{tabular}{|c|c|c|c|c|c|c|}
\hline \multicolumn{2}{|c|}{ Departments } & $\mathrm{N}$ & & \multicolumn{3}{|c|}{ S } \\
\hline \multicolumn{2}{|c|}{ Pre-school } & 36 & \multicolumn{2}{|c|}{80,4167} & \multicolumn{2}{|c|}{24,19962} \\
\hline \multicolumn{2}{|c|}{ CIT } & 141 & \multicolumn{2}{|c|}{71,3404} & \multicolumn{2}{|c|}{24,31573} \\
\hline \multicolumn{2}{|c|}{ Art } & 40 & \multicolumn{2}{|c|}{75,7750} & \multicolumn{2}{|c|}{22,67438} \\
\hline \multicolumn{2}{|c|}{ Total } & 217 & \multicolumn{2}{|c|}{73,6636} & \multicolumn{2}{|c|}{24,14313} \\
\hline & $\begin{array}{l}\text { Variance } \\
\text { Resource }\end{array}$ & $\begin{array}{l}\text { Total of } \\
\text { Squares }\end{array}$ & sd & $\begin{array}{c}\text { Average of } \\
\text { Squares }\end{array}$ & $\mathrm{F}$ & $\mathrm{p}$ \\
\hline \multirow{3}{*}{ Department } & Inter-groups & 2581,058 & 2 & 1290,529 & 2,239 & , 109 \\
\hline & Intra-groups & 123323,385 & 214 & 576,277 & & \\
\hline & Total & 125904,442 & 216 & & & \\
\hline
\end{tabular}

As it is clear in Table 5, according to the findings obtained using the single factoral variance analysis (ANOVA) for unrelated samples, there isn't any reasonable difference among the 
grades of participants in terms of their departments $[\mathrm{F}(2-214)=2,239, \mathrm{p}>.05]$. In other words, the smart phone dependencies of the participants don't differ in terms of their departments. Table 6 includes the findings concerning whether the grades which participants obtained from the smart phone dependency scale reasonably differ or not in terms of the classes of students.

Table 6. Results of grades according to classes

\begin{tabular}{|c|c|c|c|c|c|c|}
\hline \multicolumn{2}{|r|}{ Classes } & $\mathrm{N}$ & \multicolumn{2}{|c|}{$X$} & \multicolumn{2}{|c|}{$\mathrm{S}$} \\
\hline \multicolumn{2}{|r|}{1} & 37 & \multicolumn{2}{|c|}{80,9730} & \multicolumn{2}{|c|}{24,09989} \\
\hline \multicolumn{2}{|r|}{2} & 71 & \multicolumn{2}{|c|}{73,6056} & \multicolumn{2}{|c|}{27,80158} \\
\hline \multicolumn{2}{|r|}{3} & 109 & \multicolumn{2}{|c|}{71,2202} & \multicolumn{2}{|c|}{21,13947} \\
\hline \multicolumn{2}{|r|}{ Total } & 217 & \multicolumn{2}{|c|}{73,6636} & \multicolumn{2}{|c|}{24,14313} \\
\hline & $\begin{array}{l}\text { Variance } \\
\text { Resource }\end{array}$ & $\begin{array}{l}\text { Total of } \\
\text { Squares }\end{array}$ & sd & $\begin{array}{c}\text { Average of } \\
\text { Squares }\end{array}$ & $\mathrm{F}$ & $\mathrm{p}$ \\
\hline \multirow{3}{*}{ Class } & Inter-groups & 2627,796 & 2 & 1313,898 & 2,281 &, 105 \\
\hline & Intra-groups & 123276,646 & 214 & 576,059 & & \\
\hline & Total & 125904,442 & 216 & & & \\
\hline
\end{tabular}

As it is clear in Table 6, according to the findings obtained using the single factoral variance analysis (ANOVA) for unrelated samples, there isn't any reasonable difference among the grades of participants in terms of their classes $[\mathrm{F}(2-214)=2,281, \mathrm{p}>.05]$. In other words, the smart phone dependencies of the participants don't differ in terms of their classes. Table 7 includes the findings concerning whether the grades which participants obtained from the smart phone dependency scale reasonably differ or not according to the weekly internet usage durations of students.

Table 7. Results of grades according to weekly internet usage durations

\begin{tabular}{|c|c|c|c|c|c|c|}
\hline \multicolumn{2}{|c|}{$\begin{array}{c}\text { Weekly Internet Usage } \\
\text { Durations }\end{array}$} & $\mathrm{N}$ & \multicolumn{2}{|c|}{$\bar{X}$} & \multicolumn{2}{|c|}{$S$} \\
\hline \multicolumn{2}{|c|}{$0-3$ hours } & 23 & \multicolumn{2}{|c|}{71,3043} & \multicolumn{2}{|c|}{21,26336} \\
\hline \multicolumn{2}{|c|}{ 3-6 hours } & 50 & \multicolumn{2}{|c|}{70,4600} & \multicolumn{2}{|c|}{28,50579} \\
\hline \multicolumn{2}{|c|}{ 6-9 hours } & 45 & \multicolumn{2}{|c|}{68,6222} & \multicolumn{2}{|c|}{23,05851} \\
\hline \multicolumn{2}{|c|}{9 hours and over } & 99 & \multicolumn{2}{|c|}{78,1212} & \multicolumn{2}{|c|}{22,35944} \\
\hline \multicolumn{2}{|c|}{ Total } & 217 & \multicolumn{2}{|c|}{73,6636} & \multicolumn{2}{|c|}{24,14313} \\
\hline & $\begin{array}{l}\text { Variance } \\
\text { Resource }\end{array}$ & $\begin{array}{l}\text { Total of } \\
\text { Squares }\end{array}$ & $\mathrm{sd}$ & $\begin{array}{c}\text { Average of } \\
\text { Squares }\end{array}$ & $\mathrm{F}$ & $\mathrm{p}$ \\
\hline Weekly & Inter-groups & 3752,030 & 3 & 1250,677 & 2,281 & ,091 \\
\hline Internet & Intra-groups & 122152,413 & 213 & 573,486 & & \\
\hline Usage & Total & 125904,442 & 216 & & & \\
\hline Durations & Total & 125904,442 & 216 & & & \\
\hline
\end{tabular}

As it is clear in Table 7, according to the findings obtained using the single factoral variance analysis (ANOVA) for unrelated samples, there isn't a reasonable difference among the grades of participants in terms of their weekly internet usage durations $[F(3-213)=2,181$, p >.05]. In other words, the smart phone dependencies of the participants don't differ in terms of their weekly internet usage durations. Table 8 includes the findings concerning whether the grades which participants obtained from the smart phone dependency scale reasonably differ or not according to the socio-economic levels of students.

Table 8. Results of grades according to socio-economic levels

$\begin{array}{llll}\text { Socio-economic levels } & \mathrm{N} & \bar{X} & \mathrm{~S}\end{array}$




\begin{tabular}{|c|c|c|c|c|c|c|}
\hline & Good & 30 & \multicolumn{2}{|c|}{73,1000} & \multicolumn{2}{|c|}{23,69250} \\
\hline & Medium & 179 & \multicolumn{2}{|c|}{73,4302} & \multicolumn{2}{|c|}{24,40159} \\
\hline & Bad & 8 & \multicolumn{2}{|c|}{81,0000} & \multicolumn{2}{|c|}{21,34077} \\
\hline \multicolumn{2}{|r|}{ Total } & 217 & \multicolumn{2}{|c|}{73,6636} & \multicolumn{2}{|c|}{24,14313} \\
\hline & $\begin{array}{l}\text { Variance } \\
\text { Resource }\end{array}$ & $\begin{array}{l}\text { Total of } \\
\text { Squares }\end{array}$ & sd & $\begin{array}{c}\text { Average of } \\
\text { Squares }\end{array}$ & $\mathrm{F}$ & $\mathrm{p}$ \\
\hline \multirow{3}{*}{$\begin{array}{l}\text { Socio- } \\
\text { economic } \\
\text { levels }\end{array}$} & Inter-groups & 449,865 & 2 & 224,933 & ,384 & ,682 \\
\hline & Intra-groups & 125454,577 & 214 & 586,236 & & \\
\hline & Total & 125904,442 & 216 & & & \\
\hline
\end{tabular}

As it is clear in Table 8, according to the findings obtained using the single factoral variance analysis (ANOVA) for unrelated samples, there isn't a reasonable difference among the grades of participants in terms of their socio-economic levels [F(2-214)=,384 p>.05]. In other words, the smart phone dependencies of the participants don't differ in terms of their socioeconomic levels. Table 9 includes the findings concerning whether the grades which participants obtained from the smart phone dependency scale reasonably differ or not according to the genders of students.

Table 9. Results of grades according to genders

\begin{tabular}{ccccccc}
\hline Groups & $\mathrm{N}$ & $\bar{X}$ & $\mathrm{~S}$ & $\mathrm{Sd}$ & $\mathrm{t}$ & $\mathrm{p}$ \\
\hline Male & 64 & 70,5313 & 21,41648 & 215 & $-1,238$ &, 217 \\
Female & 153 & 74,9739 & 25,14666 & & & \\
\hline$* \mathrm{P}<0.05$ & & & & & &
\end{tabular}

As it is clear in Table 9, the result is not reasonable because it is $.217>.05$ for $* \mathrm{p}<.05$ relevance level. The average of grades which participants obtained as a result of smart phone dependency scale are near to each other (average of males is $=70,53$; average of females is $=74,97$ ), thus as it is clear in Table 9 , the result is $.217>.05$ for $* \mathrm{p}<.05$ relevance level so the result is not reasonable. In other words, the grades participants obtained don't differ reasonably in terms of their genders. Table 10 includes the findings concerning whether the grades which participants obtained from the smart phone dependency scale reasonably differ or not according to the internet possession situations of students.

Table 10. Results of grades according to internet possession situations

\begin{tabular}{ccccccc}
\hline $\begin{array}{c}\text { Internet } \\
\text { possession }\end{array}$ & $\mathrm{N}$ & $\bar{X}$ & $\mathrm{~S}$ & $\mathrm{Sd}$ & $\mathrm{t}$ & $\mathrm{p}$ \\
\hline Yes & 199 & 73,6784 & 24,33825 & 215 & 0,30 &, 976 \\
No & 18 & 73,5000 & 22,51601 & & & \\
\hline$* \mathrm{P}<0.05$ & & & & &
\end{tabular}

The average of grades which participants obtained as a result of smart phone dependency scale are near to each other (average of those who possess internet is $=73,67$; average of those who don't possess internet is $=73,50$ ), thus as it is clear in Table 10, the result is $.976>.05$ for $* \mathrm{p}<.05$ relevance level so the result is not reasonable. In other words, the grades participants obtained don't differ reasonably in terms of their situations of internet possession.

\section{Conclusion and Suggestions}

According to the results of this study, among the students who participated in the study, 64 are male $(29,5 \%)$ and 153 are female (70,5\%). among 217 students who participated in the study, 199 have access to internet $(91,7 \%)$ while 18 don't have $(8,3 \%)$. Among 217 students who participated in the study, 23 use 0-3 hours of internet weekly, 50 use 3-6 hours, 45 use 6-9 hours and 99 use 9 hours and over. Among 217 students who participated in the study, 36 receive education in the Pre-school Teaching Department, 141 in CIT Teaching 
Department, 40 in Art Teaching Department. According to the findings obtained using the single factoral variance analysis (ANOVA) for unrelated samples, there isn't any reasonable difference among the grades of participants in terms of their departments $[F(2-214)=2,239$, $\mathrm{p}>$.05]. there isn't any reasonable difference among the grades of participants in terms of their classes $[F(2-214)=2,281, p>.05]$. In other words, the smart phone dependencies of the participants don't differ in terms of their classes. there isn't a reasonable difference among the grades of participants in terms of their weekly internet usage durations $[F(3-213)=2,181$, $\mathrm{p}>.05]$. In other words, the smart phone dependencies of the participants don't differ in terms of their weekly internet usage durations. there isn't a reasonable difference among the grades of participants in terms of their socio-economic levels $[F(2-214)=, 384 p>.05]$. In other words, the smart phone dependencies of the participants don't differ in terms of their socio-economic levels. the result is $.217<.05$ for $* \mathrm{p}<.05$ relevance level so the result is not reasonable. In other words, the grades participants obtained don't differ reasonably in terms of their genders. the result is $.976>.05$ for $* \mathrm{p}<.05$ relevance level so the result is not reasonable. In other words, the grades participants obtained don't differ reasonably in terms of their situations of internet possession. In the other words, according to the results of this study which aims the determination of smart phone usages of the workgroup consisting of prospective instructors receiving education in different departments of faculty of education, smart phone dependencies of participant students don't demonstrate any meaningful variations in terms of classes and departments, socio-economic levels, weekly internet usage durations and internet possession situations of the participants. In other words, the smart phone dependencies of the participants don't differ in terms of their genders, classes and departments, socio-economic levels, weekly internet usage durations and internet possession situations. It is also possible to run across similar or different results in the literature. It can be stated that this result is originated from some factors such as cities of accommodation, monthly income situations, education levels, social environments, social media usage levels of the workgroup.

Consequently, when considered that smart phones which prospective instructors use are mobile learning devices, it can be stated that the education of prospective instructors is not being debated sufficiently in the literature. Taking account the results of this study, it is possible to define today's students as youngsters of digital generation who are more eager to digital learning. In other words, modern-day youngsters are quite prone to mobile learning environments and the inter-individual differences are not much. In the circumstances, the analysis of the following issues is suggested; the effects of mobile learning on various variables by discussing mobile learning in different lessons with different design approaches, which design principles shall be taken into account while designing a mobile environment, which education design approach shall be preferred for an education, how to integrate these technologies into educational programs and analysis of mobile learning environments in terms of individual differences, etc.

\section{References}

Campbell, S.W. (2007). A cross-cultural comparison of perceptions and uses of mobile telephony, New Medoa Society, Vol. 9 No. 2, pp. 343-63.

Cochrane, T. (2010). Mobile web 2.0: Bridging learning contexts. In S. Caballé, F. Xhafa, T. Daradoumis, \& A. A. Juan, Architectures for distributed and complex m-learning systems: Applying intelligent technologies (s. 123-151). UAS: Information Science Reference.

Çakır, H. (2011). A software development and evaluation of mobile learning. Cukurova University Faculty of Education Journal. 40, 01-09. 
Demirci, K., Orhan, H., Demirdas, A., Akpınar, A., \& Sert, H. (2014). Validity and reliability of the turkish version of the smartphone addiction scale in a younger population. Bulletin of Clinical Psychopharmacology, 24(3), 226-34.

DSM-IV-TR (2005). Handbook of Diagnostic Criteria Reference Manual. (Translation: Ertuğrul Köroğlu). Ankara: Hekimler Publishing.

Hjorthol, R. J. (2008). The mobile phone as a tool in family life: impact on planning of everyday activities and car use, Transport Review, Vol. 28, No. 3, pp. 303-20.

Kim, S. H. (2008). Moderating effects of job relevance and experience on mobile wireless technology acceptance: adoption of a smartphone by individuals, Information and Management, Vol. 45, pp. 387-93.

Korkmaz, Ö. (2015). New Trends on Mobile Learning in The Light of Recent Studies, Participatory Educational Research (PER) Vol. 2(1), pp. 1-10.

Oran, M. K. and Karadeniz, SS. (2007). The role of mobile learning role in intenet based distance education. Available at: http://ab.org.tr/ab07/bildiri/66.pdf.

Park, Y. and Chen, J.V. (2007). Acceptance and adoption of the innovative use of smartphone, Industrial Management and Data, Vol. 107 No. 9, pp. 1349-65.

Quinn, C. N. (2000). mLearning: Mobile, wireless, in-your-pocket learning. http://www.linezine.com/2.1/features/cqmmwiyp.htm.

Saran, M., Seferoğlu, G., \& Çă̆ıltay, K. (2009). Mobile assisted language learning: English pronunciation at learners' fingertips. Eurasian Journal of Educational Research, 34, 97-114.

Sharples, M., Taylor, J., \& Vavoula, G. (2005). Towards a Theory of Mobile Learning. In Proceedings of m-learn Conference, Cape Town: 2005, South Africa.

Taner, N. (2013). User reviews of Smart Phones: An Application in the city center of Kastamonu, Business \& Management Studies: An International Journal, 1(2).

Wilson, S. and McCarthy, G. (2010). The mobile university: from library to the campus, Reference Services Review, Vol. 38 No. 2, pp. 1-39. 